http://jmscr.igmpublication.org/home/ ISSN (e)-2347-176x ISSN (p) 2455-0450

crossref DOI: https://dx.doi.org/10.18535/jmscr/v8i2.111

Journal Of Medical Science And Clinical Research

\title{
Comparative study of hemodynamics in Intracranial tumor surgeries with clonidine and dexmedetomidine under general anesthesia
}

\author{
Authors \\ Dr P.V.Sairam ${ }^{1}$, Dr B. Murali Krishna ${ }^{2}$, Dr K.Praveen ${ }^{4}$
}

\begin{abstract}
Background and Aim: Perioperative hemodynamic stability is of extreme importance while administering general anesthesia to avoid intracranial hemorrhage to profound surgical stimuli associated with craniotomy. Recently alpha 2 agonists clonidine and dexmedetomidine are being used for attenuating these hemodynamic responses. As no studies compared them using intraoperative infusions throughout surgery present study is designed so.

Materials and methods: 60 patients diagnosed with intracranial tumors are randomized into two Groups of $C$ and $D$ of each 30. Group C received clonidine as a bolus of $0.5 \mathrm{mic} / \mathrm{kg}$ intravenously (IV) $20 \mathrm{minutes}$ before induction and intra-operatively iv infusion at $0.5 \mathrm{mic} / \mathrm{kg} / \mathrm{hr}$ after intubation and stopped before starting of skin closure. Similarly, Group D receives Dexmedetomidine at the same doses and same time.Hemodynamics like heart rate and mean arterial blood pressure at intubation, craniotomy, and extubation and side effects of study drugs like bradycardia and hypotension compared.

Results: At intubation, the mean heart rate in Group $C$ is $79.36 \pm 7.328$ beats/ min, and in Group D is $74.33 \pm 6.07, p$ valve for mean heart rate is $0.0053(S)$. Mean MAP at intubation in Group C is $80.5 \pm$ $7.645 \mathrm{~mm} \mathrm{Hg}$, and in Group D is $72.47 \pm 5.869$ is $0.0001(\mathrm{~S})$. The mean heart rate at extubation in Group $C$ is $71.16 \pm 3.355$, and in group D $68.57 \pm 4.56$, and the p-value is 0.0149(S). Mean MAP at extubation in Group C is 71.1 \pm 4.278 , and in Group D is $69.03 \pm 2.456$, and p-value is 0.02733 (S). 2 persons from Group C and 5 from Group D had bradycardia and 3 in Group C, and 4 in Group D had hypotension episodes, and $p$ valve is 0.13 and $0.68(N S) . P$ valve $<0.05$ statistically significant $(S)$ and > 0.05 satistiocally nonsignificant (NS).

Conclusion: Both drugs caused attenuation of sympathetic responses like heart rate and mean arterial pressure in Intracranial tumor surgeries with an excellent operating field; however, dexmedetomidine is a preferable agent when compared to clonidine, with better hemodynamic stability and a bright surgical condition.
\end{abstract}

\section{Introduction}

Hemodynamic stability in the perioperative period is of prime importance while providing general anesthesia in cranial tumor surgeries. Profound surgical stimuli associated with craniotomy often result in sympathetic activation ${ }^{1}$ and marked changes in arterial blood pressure, cerebral blood flow, and thereby changes in intracranial pressure and cerebral perfusion pressure. Goals during neurosurgical anesthesia are intraoperative hemodynamic stability with attenuation of sympathetic responses to avoid intracranial hemorrhage and to allow immediate neurological evaluation upon emergence ${ }^{2}$.

Excessive blood in the field of operation hinders visibility, which may lead to increased blood loss. 
Various agents used to achieve controlled hypotension to limit intraoperative blood loss were associated with disadvantages, that include rebound hypertension from beta-blockers ${ }^{3}$, delayed recovery from inhaled anesthetics, resistance to vasodilators, and cyanide toxicity for nitroprusside ${ }^{4}$. Selective $\boldsymbol{\alpha}_{\mathbf{2}}$ adrenergic receptor agonists clonidine and dexmedetomidine are being used as hypotensive agents in the last two decades.

In the recent decade, several studies have focused on clonidine and recently on dexmedetomidine as premedication to attenuate the hemodynamic responses following intubation. However, there was no comparative study between clonidine and dexmedetomidine in craniotomy cases and administering them as intraoperative infusion throughout surgery for hemodynamic stability.

This study primarily aims to assess and compare the hemodynamic effects of intravenous clonidine and intravenous dexmedetomidine in intracranial tumor surgeries under general anesthesia.

\section{Materials and Methodology}

The present study was done in 60 patients diagnosed with an intracranial tumor in Tertiary care hospital, North Coastal Andhra Pradesh, from January 2018 to August 2019. Before the study, permission from the Institutional Scientific and Ethics Committee and written consent from patients participating in the study after explaining them about the study in their language were taken. Inclusion criteria in the study were patients aged between 18 and 65 yrs, diagnosed with an intracranial tumor, physical status system classification by American Society Of Anaesthesiologists 1 and 2, Mallampati score of Airway 1 and 2 and posted for elective surgery. Patients who are associated with morbid obesity cerebrovascular disease, renal disease, hepatic disease, with heart rate less than 60 , ejection fraction less than $45 \%$ were excluded. Pregnant and lactating mothers, coagulopathic, psychiatry patients, and who participated in any other study in the last month were excluded.
All 60 patients in the study were evaluated with detail history, general, and systemic examination and were divided randomly into two groups; Group C and Group D of 30 each. Randomization was done before starting the study with the preallocation of a patient into a group using computer-generated randomization. On arrival in the operating room, the patient data confirmed, and baseline parameters were noted after $5 \mathrm{~min}$ of settling. A large-bore intravenous (IV) $18 \mathrm{G}$ cannula was inserted. Under LA and aseptic precautions, a central venous line was secured in the right subclavian vein using a modified Seldinger technique and for invasive arterial blood pressure (Mindray) monitoring, left radial artery cannulated.

All the patients in Group $\mathrm{C}$ received Inj. Clonidine of $0.5 \mathrm{mic} / \mathrm{kg}$ and similarly, Group D patients received Inj. Dexmedetomidine of $0.5 \mathrm{mic} / \mathrm{kg}$ IV 20 minutes before the induction of anesthesia. All patients were premedicated with Inj. Glycopyrrolate $0.2 \mathrm{mg}$ IV, Inj. Fentanyl two $\mu \mathrm{g} / \mathrm{kg}$ and Inj.Midazolam $1 \mathrm{mg}$ IV 5 minutes before induction and induced with Inj. Thiopentone sufficient to abolish eyelash reflex, followed by Inj.Vecuronium $0.1 \mathrm{mg} / \mathrm{kg}$ to facilitate tracheal intubation, which was done with an appropriate size endotracheal tube.

Anesthesia was maintained with controlled mechanical ventilation, $\mathrm{N} 2 \mathrm{O}$ in $\mathrm{O} 2$ (60:40), Isoflurane $1 \%$, Inj. Fentanyl $1 \mu \mathrm{g} / \mathrm{kg}$, and Inj. Vecuronium in $0.02 \mathrm{mg} / \mathrm{kg}$ boluses every 30 minutes.. All the patients in Group $\mathrm{C}$ received Inj Clonidine maintenance infusion in a dose of 0.5 $\mu \mathrm{g} / \mathrm{kg} / \mathrm{hr}$, and all patients in Group D received Inj Dexmedetomidine infusion at a dose of 0.5 $\mu \mathrm{g} / \mathrm{kg} / \mathrm{hr}$. The amount of drug needed according to weight and time was calculated and diluted in 100 $\mathrm{ml}$ normal saline and given intravenously through a syringe pump. Maintenance study drug infusion was soon started after intubation and discontinued at the start of skin closure. Similarly, isoflurane was terminated at the start of skin closure, and $\mathrm{N} 2 \mathrm{O}$ after skin closure. At the end of anesthesia, the neuromuscular blockade was antagonized with 
Inj.Neostigmine $0.04 \quad \mathrm{mg} / \mathrm{kg}$ and inj. Glycopyrrolate $0.02 \mathrm{mg} / \mathrm{kg}$ intravenously. Patients were extubated when respiration was sufficient, adequate muscle power, and patients were able to obey simple commands. At the end of the surgery, all the patients were transferred to the neurosurgical intensive care unit and monitored. All episodes of hemodynamic derangements lasting longer than 2 minutes were identified, treated, and recorded.

\section{Data Collection}

Patient details, ASA status, MPG, hemodynamic parameters like heart rate (HR), systolic blood pressure (SBP), diastolic blood pressure (DBP), mean arterial pressure (MAP), oxygen saturation (SPO2), respiratory rate (RR) at different events of surgery were entered in the proforma datasheet.

\section{Side effects of study drug}

The common side effects of the study drugs are bradycardia and hypotension. Patients requiring atropine for bradycardia (HR $<55$ beats $/ \mathrm{min}$ ) and mephenteramine for hypotension (MAP $<60 \mathrm{~mm}$ hg) were noted.

\section{Statistical Data Analysis}

Data entered in Microsoft MS Excel and analysis done in MS Excel and SPSS.Tests of significance applied where ever applicable. A p-value of 0.05 is taken as the level of significance.

\section{Results}

Table 1: Comparison of mean heart rates of Study Population in Two Groups C \& D at Different Periods During Surgery

\begin{tabular}{|l|c|c|c|c|}
\hline & $\begin{array}{c}\text { GROUP C }(\mathbf{n}=\mathbf{3 0}) \\
\text { Mean }+/ \text { - SD }\end{array}$ & $\begin{array}{c}\text { GROUP D }(\mathbf{n}=\mathbf{3 0}) \\
\text { Mean }+/ \text { - SD }\end{array}$ & P VALUE & SIGNIFICANCE \\
\hline T0 & $84.8 \pm 10.39$ & $81.86 \pm 10.51$ & 0.2804 & NS \\
\hline T1 & $79.9 \pm 8.506$ & $78.06 \pm 8.286$ & 0.3992 & NS \\
\hline T2 & $79.36 \pm 7.328$ & $74.33 \pm 6.07$ & $0.0053^{*}$ & S \\
\hline T3 & $77.93 \pm 7.042$ & $72.33 \pm 5.136$ & $0.0008^{*}$ & $\mathrm{~S}$ \\
\hline T4 & $73.63 \pm 6.348$ & $68.2 \pm 4.578$ & $0.003^{*}$ & $\mathrm{~S}$ \\
\hline T5 & $68.97 \pm 7.007$ & $64.8 \pm 5.741$ & $0.0145^{*}$ & $\mathrm{~S}$ \\
\hline T6 & $68.1 \pm 5.44$ & $64.93 \pm 5.046$ & $0.0240^{*}$ & $\mathrm{~S}$ \\
\hline T7 & $67.03 \pm 4.557$ & $66.07 \pm 4.242$ & 0.4017 & $\mathrm{NS}$ \\
\hline T8 & $71.16 \pm 3.355$ & $68.57 \pm 4.56$ & $0.0149^{*}$ & $\mathrm{~S}$ \\
\hline T9 & $73.1 \pm 4.73$ & $70.9 \pm 5.24$ & $0.0932^{*}$ & $\mathrm{~S}$ \\
\hline T10 & $75.4 \pm 4.97$ & $72.8 \pm 5.61$ & 0.0626 & $\mathrm{NS}$ \\
\hline
\end{tabular}

T0-baseline, T1-15mins after bolus, T2-At intubation, T3-5mins after intubation, T4-at Craniotomy, T5,6,7-30 mins, 90 mins, and 150 mins aft Craniotomy, T8-At extubation, T9-5mins after extubation, T10-1hr after extubation

Figure 1: Mean Heart Rates of Study Population in two groups C \& D At Different Periods During Surgery

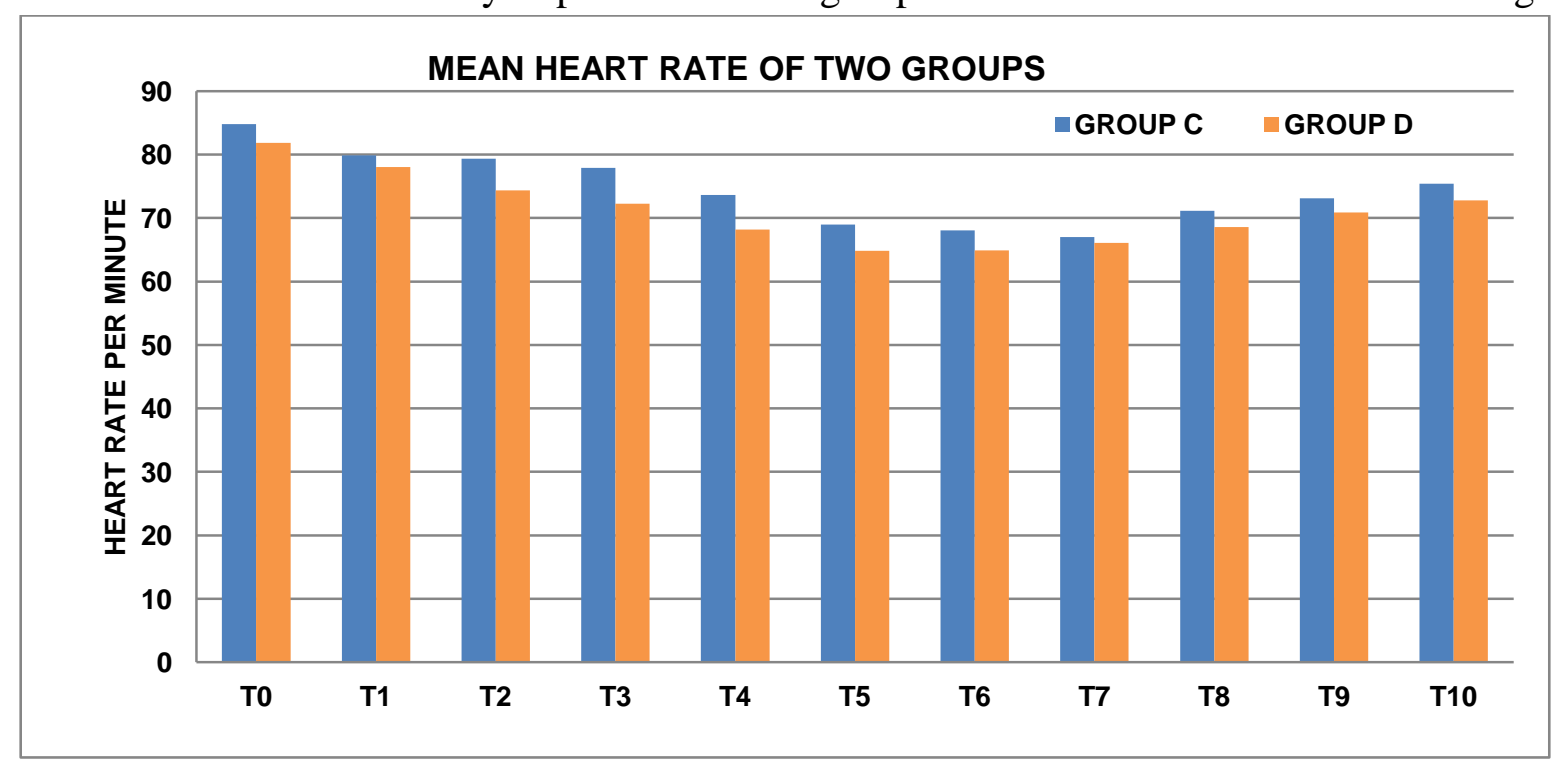

NS : Non Significant ( $\mathrm{p}$ value $>0.05) ; \mathrm{S}, *$ : Significant ( $\mathrm{p}$ valve $<0.05$ ) 
Figure 2: Mean Heart Rates of Study Population in two groups C \& D At Different Periods During Surgery

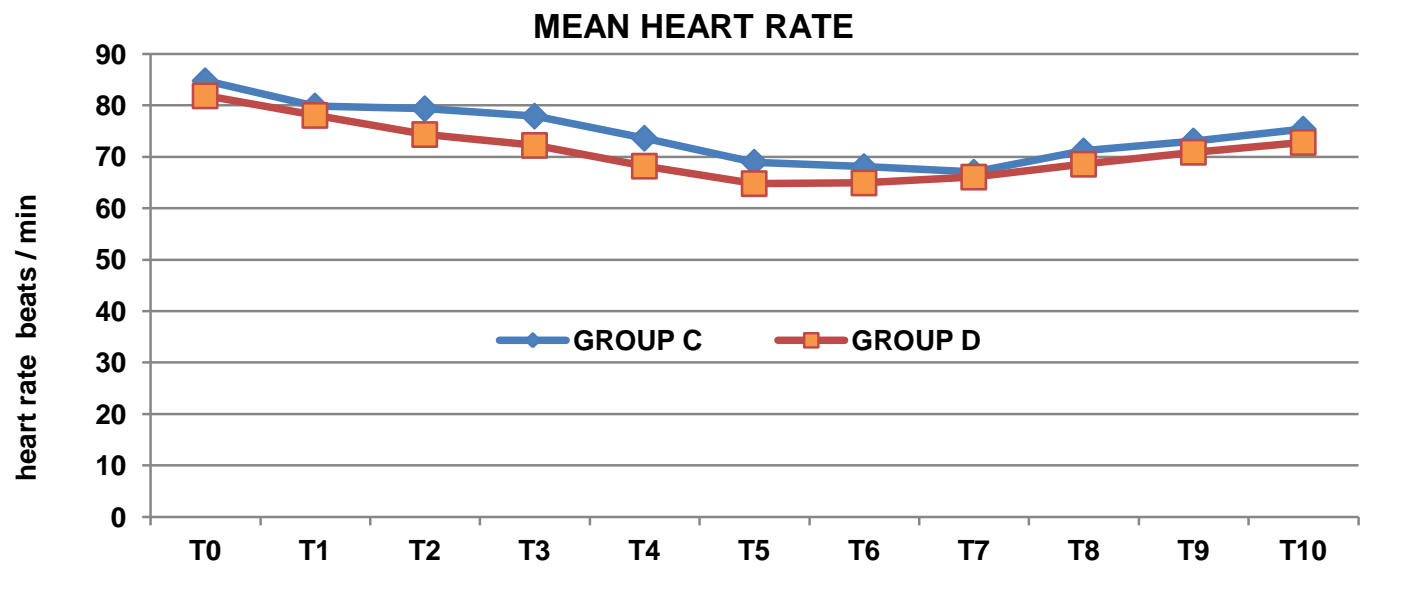

NS : Non Significant ( $p$ value $>0.05) ; S, *:$ Significant $(\mathrm{p}$ valve $<0.05$ )

Table 8: Mean of Mean Arterial Pressures of Study Population in two Groups C \& D At Different Periods During Surgery

\begin{tabular}{|l|c|c|c|c|}
\hline & $\begin{array}{c}\text { GROUP C }(\mathbf{n}=30) \\
\text { Mean +/- SD }\end{array}$ & $\begin{array}{c}\text { GROUP D }(\mathbf{n = 3 0}) \\
\text { Mean +/- SD }\end{array}$ & P VALUE & SIGNIFICANCE \\
\hline T0 & $86.733 \pm 9.25$ & $85.433 \pm 9.290$ & 0.5891 & NS \\
\hline T1 & $76.17 \pm 7.029$ & $72.7 \pm 6.64$ & 0.0541 & NS \\
\hline T2 & $80.5 \pm 7.645$ & $72.47 \pm 5.869$ & $0.0001^{*}$ & S \\
\hline T3 & $79.37 \pm 9.279$ & $71.43 \pm 5.207$ & $0.0001 *$ & S \\
\hline T4 & $76.27 \pm 8.45$ & $69.53 \pm 4.072$ & $0.0002^{*}$ & S \\
\hline T5 & $72.367 \pm 7.167$ & $66.667 \pm 3.33$ & $0.0002^{*}$ & S \\
\hline T6 & $70.4 \pm 6.317$ & $66.1 \pm 3.33$ & $0.0017 *$ & $\mathrm{~S}$ \\
\hline T7 & $69.93 \pm 5.164$ & $67.77 \pm 2.186$ & $0.0392^{*}$ & $\mathrm{~S}$ \\
\hline T8 & $71.1 \pm 4.278$ & $69.03 \pm 2.456$ & 0.02733 & $\mathrm{~S}$ \\
\hline T9 & $72.27 \pm 5.033$ & $70.27 \pm 2.462$ & 0.0543 & $\mathrm{NS}$ \\
\hline T10 & $73.07 \pm 4.45$ & $72.6 \pm 4.484$ & 0.6854 & $\mathrm{NS}$ \\
\hline
\end{tabular}

NS : Non Significant ( p-value $>0.05$ ); , * :Significant ( p valve $<0.05$

Figure 3: Comparison of mean of mean Arterial Pressures of Study Population in two Groups C \& D At Different Times During Surgery

MEAN ARTERIAL PRESSURES

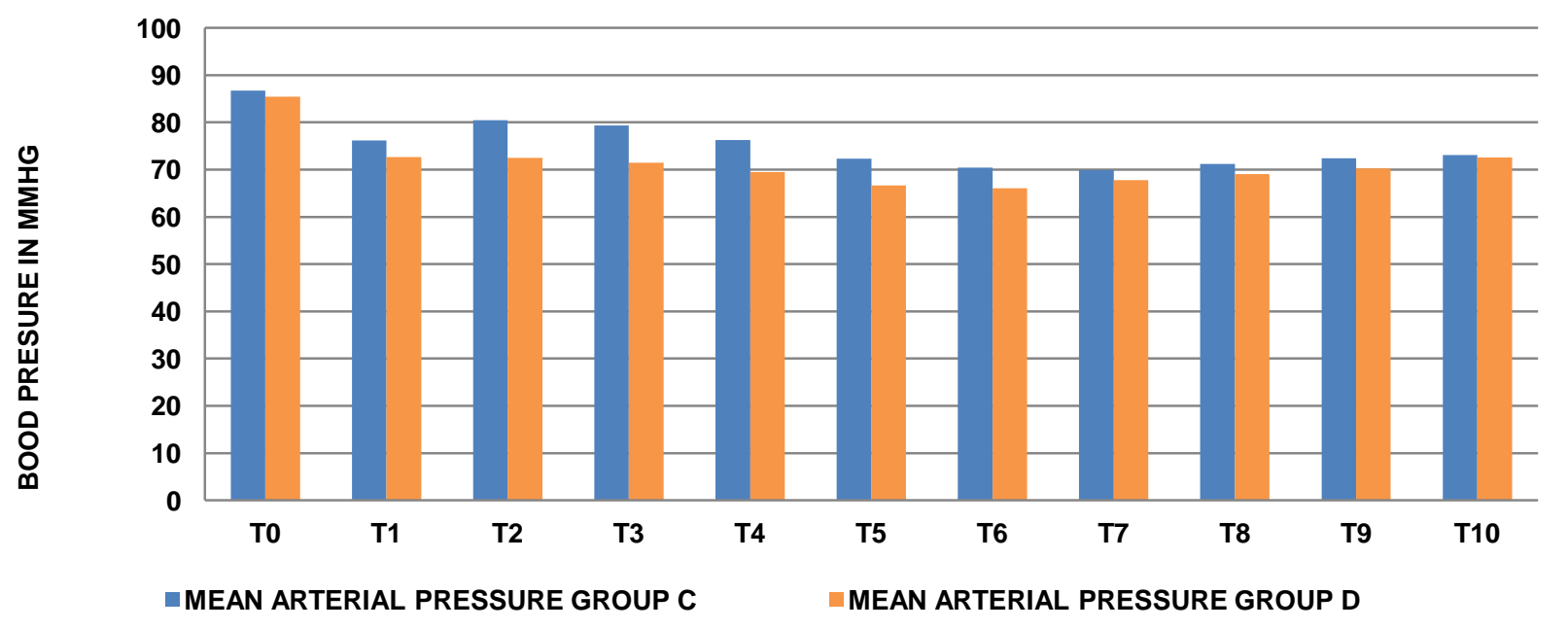

NS : Non Significant ( $p$ value $>0.05) ; S, *$ : Significant $(\mathrm{p}$ valve $<0.05$ ) 
Figure 4: Comparison of mean Arterial Pressures of Study Population in two Groups C \& D At Different Times During Surgery

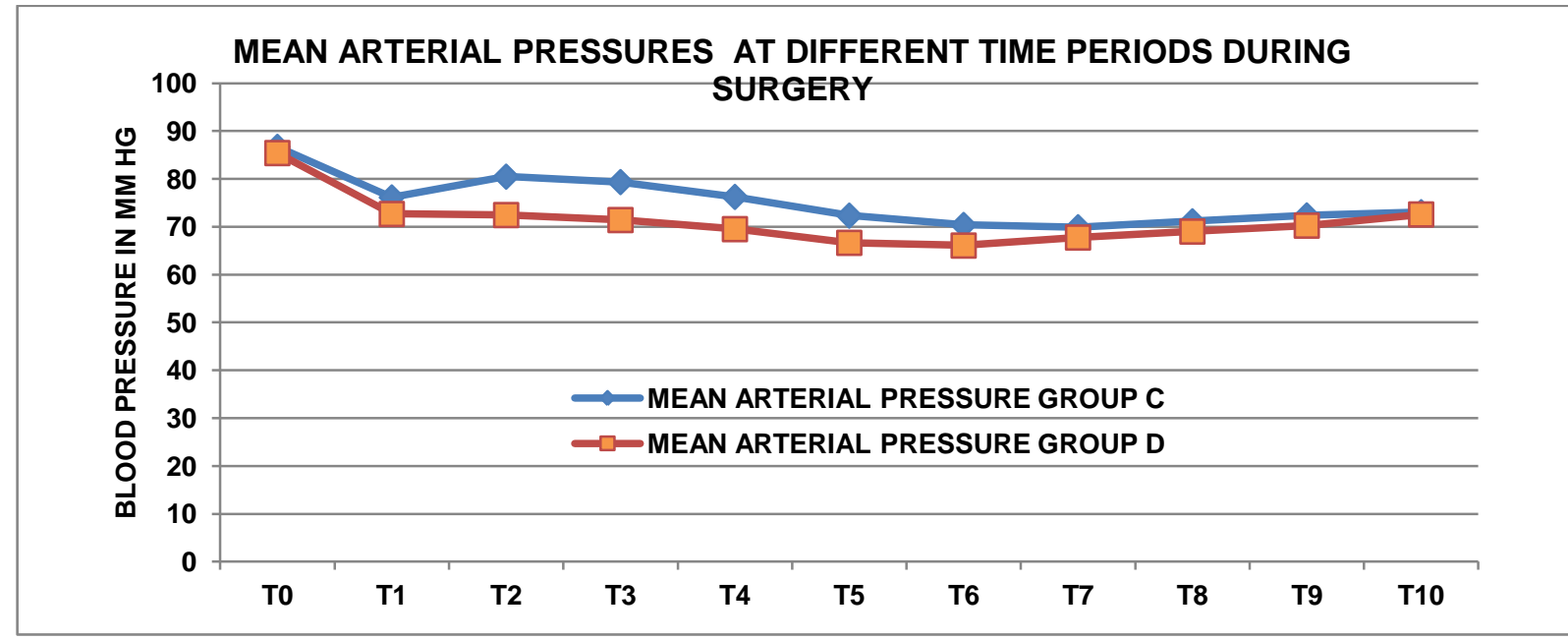

NS : Non Significant ( $p$-value $>0.05) ; \mathrm{S}, *$ : Significant $(\mathrm{p}$ valve $<0.05$ )

Table 3: Comparison of Side Effects of Study Drugs in Study Population

\begin{tabular}{|l|c|c|c|c|}
\hline & $\begin{array}{c}\text { GROUP C } \\
(\mathbf{n = 3 0})\end{array}$ & $\begin{array}{c}\text { GROUP D } \\
(\mathbf{n = 3 0})\end{array}$ & P VALUE & SIGNIFICANCE \\
\hline $\begin{array}{l}\text { BRADYCARDIA } \\
(<\mathbf{5 5} \text { beats /MIN })\end{array}$ & $2(6.67 \%)$ & $5(20 \%)$ & 0.1371 & NS \\
\hline $\begin{array}{l}\text { HYPOTENSION } \\
(<\mathbf{6 0} \text { mm Hg) }\end{array}$ & $3(10 \%)$ & $4(13.34 \%)$ & 0.6895 & NS \\
\hline
\end{tabular}

Figure 5: Comparison of Side Effects of Drugs in Study Population

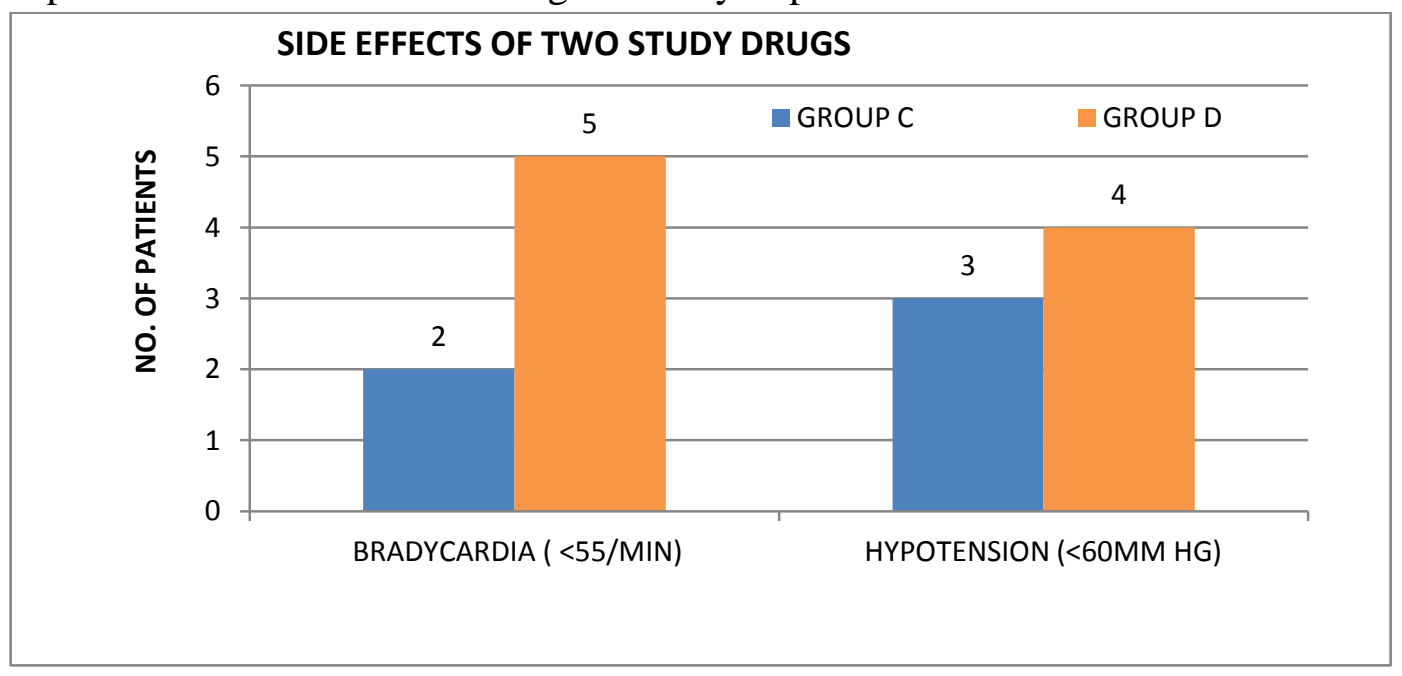

\section{Discussion}

Perioperative hemodynamic stability is one of the essential concepts in providing anesthesia to intracranial tumor surgery. Surgical stimuli associated with craniotomy results in marked changes in arterial blood pressure and intracranial pressure (ICP) $)^{1}$. Alpha 2 agonists act on $\alpha_{2}$ adrenergic receptors in the locus coeruleus, provides relatively fast onset of sedative properties. They have sympatholytic properties with anesthetic sparing effect, sedative, analgesic properties without significant respiratory depression. They provide excellent perioperative hemodynamic stability with decreased intraoperative opioid requirements.

The mean age of study population in Clonidine Group C was $41.87+/-12.73$ years, and in Dexmedetomidine Group D was $42.93+/-12.37$ 
years_The mean weight of patients in Group C was $64.6+/-9.62 \mathrm{~kg}$. The mean weight of patients in Group D was $63.6+/-10.1 \mathrm{~kg}$. In Group C, there were 16(53.34\%)males and $14(46.67 \%)$ females. In Group D, there were $17(56.67 \%)$ males and $13(43.34 \%)$ females. The mean duration of surgery in Clonidine Group $\mathrm{C}$ was $178.26+/-8.85$ minutes, and in Dexmedetomidine Group D was 174.96 +/- 5.25 minutes.

Thus demographic data like age, sex, and weight; patient characteristics like ASA and MPG, baseline parameters for hemodynamic variables like heart rate, systolic blood pressures, diastolic blood pressures, mean arterial pressures were statistically comparable in the two groups

At intubation, the mean heart rate in Group C is $79.36 \pm 7.328$ minutes, mean arterial pressures in Group $\mathrm{C}$ is $80.5 \pm 7.645 \mathrm{~mm}$ hg which are less than the baseline mean HR $84.8 \pm$ 10.39 and MAP 86.733 \pm 9.25 respectively, implying the effectiveness of clonidine on hemodynamic responses, which is mostly due to the bolus dose given 20minutes before induction and suggesting its use as premedication. These present study results were comparable with studies of Gupta et al. ${ }^{5}$ and Jitin Bajaj et al. ${ }^{6}$, where they used clonidine as premedication orally at varying doses at different times in the preoperative period. Moreover, in present study, we used a bolus dose of IV clonidine $0.5 \mathrm{mic} / \mathrm{kg}$ 20 minutes before induction, which also exhibited similar results. Higher doses of clonidine in Jitin Bajaj et al. ${ }^{6}$ study showed adverse effects, which implies the dose-dependent decrease in heart rate and mean arterial pressures.

At intubation, the mean heart rate in Group D is $74.33 \pm 6.07$ minutes, and mean arterial pressures in Group D is $72.47 \pm 5.869$, a significant reduction from baseline $\operatorname{HR}(81.86 \pm$ $10.51)$, and baseline MAP $(85.433 \pm 9.290)$ were observed. Thus dexmedetomidine is also useful in attenuating the hemodynamic responses to laryngoscopy and intubation. Our study results were in concurrence to the study results of Uyar et al. ${ }^{7}$, where they used @ 1mic/kg dose (higher dose than present study) as premedication to blunt the intubation responses. The study results were also more similar to Keshri et al. ${ }^{8}$ low dose dexmedetomidine group.

When both groups C and D were compared for the mean heart rate and mean MAP at intubation, both are effective in attenuating the intubation response.but the $\mathrm{p}$ valve for mean heart rate is 0.0053 and $p$ valve for MAP is $0.0001(<0.05)$ which are statistically significant. It indicates that Group D is superior to Group C in attenuating the hemodynamic responses to laryngoscopy and intubation. Our study results were similar to studies of Sarkar et al. ${ }^{9}$ and Jan et al. ${ }^{10}$. So, dexmedetomidine is superior to clonidine in attenuating the hemodynamic responses to intubation as it has high alpha 2 binding selectivity compared to clonidine.

In the present study, the mean heart rate and mean arterial pressures of both groups $\mathrm{C}$ and $\mathrm{D}$ decreased gradually and were maintained in the normal range throughout the intraoperative period soon after skin incision to closure. When they were compared in both groups, a p-value of less than 0.05 was observed at periods like skin incision T3, at craniotomy T4 and intraoperatively $\mathrm{T} 5$ to $\mathrm{T} 8$, and thus dexmedetomidine group showed better hemodynamic control than clonidine group. These results were in concurrence with the studies of Nalini Jadhav et al. ${ }^{11}$ and Tanskanen PE et al. ${ }^{12}$

The mean heart rate at extubation in group $\mathrm{c}$ is $71.16 \pm 3.355$, and in group D $68.57 \pm 4.56$. The p-value is 0.0149 , which is statistically significant. The mean MAP at extubation in Group $\mathrm{C}$ is $71.1 \pm$ 4.278, and in Group D is $69.03 \pm 2.456$. The pvalue is $0.02733(<0.05)$ and was statistically significant. It implies that in Group D is better in attenuation of extubation response had occurred

Our observations at extubation were in concurrence to the studies of Dilip Kotari et al. ${ }^{13}$ with similar doses of dexmedetomidine and also in concurrence with Talke et al. ${ }^{14}$, where dexmedetomidine had a lesser increase in mean 
arterial pressure and heart rate for extubation responses.

In our study, two persons in Group C (6.67\%) and five persons from Group D (20\%) had bradycardia (HR $<55$ beats/min) episodes and required atropine $0.6 \mathrm{mg}$ IV. Furthermore, three persons in Group C (10 \%) and four persons $(13.33 \%)$ in Group D had hypotension episodes (MAP < 60mmhg), and required mephenteramine for correction. Our study results are similar to Soliman $\mathbf{R}$ et al. ${ }^{15}$ study concerning the side effects of dexmedetomidine.

\section{Limitations}

A small sample size limits the study. Furthermore, the study lacks a placebo group. The depth of anesthesia could not be measured as the Bispectral Index (BIS) technique has some technical problems in intracranial surgery, such as after scalp elevation (weak signal transference). Another limitation was that the effect of clonidine and dexmedetomidine on cerebral perfusion and intracranial pressure was not studied.

\section{Conclusion}

The study concludes that both dexmedetomidine and clonidine caused attenuation of sympathetic responses like heart rate and mean arterial pressure in Intracranial tumor surgeries with a good operating field, However dexmedetomidine is a preferable agent when compared to clonidine, with better hemodynamic stability and a clear surgical condition.

\section{References}

1. Miller's Anesthesia. 8th ed., Ch13, Philadelphia, PA: Elsevier Churchill Livingstone; 2015:2190-2192.

2. Favre JB, Gardaz JP, Ravussin P: Effect of clonidine on ICP and the hemodynamic responses to nociceptive stimuli in patients with brain tumors. J Neurosurg Anesthesiol; 1995, 7:159-167.

3. Pavlin JD, Colley PS, Weymuller EA Jr, Van Norman G, Gunn HC, Propofol versus isoflurane for endoscopic sinus surgery. Am J Otolaryngol 1999;20:96101.

4. Ornstein E, Young WL, Ostapkovich N, Matteo RS, Diaz J. Deliberate hypotension in patients with intracranial arteriovenous malformations: Esmolol compared with isoflurane and sodium nitroprusside.

5. Gupta D, Srivastava S, Dubey RK, Prakash PS, Singh PK, Singh U.Comparative evaluation of atenolol and clonidine premedication on cardiovascular response to nasal speculum insertion during trans-sphenoid surgery for resection of pituitary adenoma: A prospective randomized,double-blind, controlled study.Indian J Anaesth 2011;55:135-40.

6. Jitin Bajaj, Radhe Shyam Mittal \& Achal Sharma (2017) Preoperative clonidine use in trans-sphenoidal pituitary adenoma surgeries - a randomized controlled trial, British Journal of Neurosurgery, 31:1, 2-4.

7. Uyar AS, Yagmurdur $\mathrm{H}$, Fidan $\mathrm{Y}$, Topkaya C, Basar H. Dexmedetomidine attenuates the hemodynamic and neuroendocrinal responses to a skull-pin head-holder application during craniotomy. J Neurosurg Anesthesiol 2008;20:174-9.

8. Keshri RK, Prasad MK, Choudhary AK, Jheetay GS, Singh Y, Kapoor K. Comparative evaluation of different doses of intravenous dexmedetomidine on hemodynamic response during laryngoscopy and endotracheal intubation in geriatric patients undergoing spine surgeries: A prospective, double-blind study. Anesth Essays Res 2018;12:897902.

9. Sarkar A, Tripathi RK, Choubey S, Singh $\mathrm{RB}$, Awasthi S. Comparison of effects of intravenous clonidine and dexmedetomidine for blunting pressor response during laryngoscopy and tracheal 
intubation: A randomized control study. Anesth Essays Res 2014;8:361-6.

10. Jan S, Ali Z, Nisar Y, Naqash IA, Zahoor SA, Langoo SA, et al. A comparison of dexmedetomidine and clonidine in attenuating the hemodynamic responses at various surgical stages in patients undergoing elective transnasal transsphenoidal resection of pituitary tumors.Anesth Essays Res 2017;11:107983.

11. Nalini Jadhav, Nilesh Wasekar, Vinayak Wagaskar, Bharati Kondwilkar, Rajesh Patil. Use of Dexmedetomidine in Patients Undergoing Craniotomies. Journal of Clinical and Diagnostic Research. 2017 Jan, Vol-11(1): UC01-UC08.

12. Tanskanen PE, Kyttä JV, Randell TT, Aantaa RE. Dexmedetomidine as an anesthetic adjuvant in patients undergoing intracranial tumor surgery: A double-blind, randomized, and placebo-controlled study. British Journal of Anaesthesiology. 2006;97(5):658-65.

13. Kothari D, Tandon N, Singh M, Kumar A. Attenuation of circulatory and airway responses to endotracheal extubation in craniotomies for intracerebral spaceoccupying lesions: Dexmedetomidine versus lignocaine. Anesth Essays Res 2014;8:78-82.

14. Talke P, Chen R, Thomas B, Aggarwall A, Gottlieb A, Thorborg P, Heard S, Cheung A, Son SL, Kallio A. The hemodynamic and adrenergic effects of perioperative dexmedetomidine infusion after vascular surgery. Anesth Analg. 2000 Apr;90(4):834-9.

15. Suxamethonium and intubation. Saudi J Anaesth 2015;9:179-83.
16. Soliman R, Fouad E. The effects of dexmedetomidine and magnesium sulphate in adult patients undergoing endoscopic transnasal transsphenoidal resection of pituitary adenoma: A double-blind, randomized study. Indian $\mathrm{J}$ Anaesth 2017;61:410-7. 